American Journal of Infectious Diseases 5 (3): 225-230, 2009

ISSN 1553-6203

(C) 2009 Science Publications

\title{
In vitro Growth and Inhibition Studies of Monosodium Urate Monohydrate Crystals by Different Herbal Extracts
}

\author{
${ }^{1}$ Bharat B. Parekh, ${ }^{2}$ Sonal R. Vasant, ${ }^{2}$ Kashmira P. Tank, \\ ${ }^{3}$ Ashwinikumar Raut, ${ }^{3}$ Ashok D.B. Vaidya and ${ }^{2}$ Mihir J. Joshi \\ ${ }^{1}$ Institue of Petroleum Technology, \\ Pandit Deendayal Petroleum University Raisan, Gandhinagar 382007 India \\ ${ }^{2}$ Department of Physics, Crystal Growth Laboratory, \\ Saurashtra University, Rajkot 360005 India \\ ${ }^{3}$ Indian Council of Medical Research Advanced Centre for Reverse \\ Pharmacology in Traditional Medicine, Kasturba Health Society, \\ 17, Khandubhai Desai Road, Vile Parle (West) Mumbai 400056 India
}

\begin{abstract}
Problem statement: A large number of people in the world have been suffering from gout for centuries. Gout is the term given to a metabolic condition in which the signs and symptoms results from the deposition of crystals of Monosodium Urate Monohydrate (MSUM) in various connective tissues. Approach: It was quite difficult to grow good quality large MSUM crystals because uric acid was having very low solubility in any known solvents. Results: Attempts were made in the present investigation to grow MSUM crystals in vitro by single diffusion gel growth technique, which is quite suitable to mimic the growth of MSUM crystals in vivo up to a certain extent. Good quality needle type crystals were grown in the gel, which were characterized by FT-IR, Powder X-ray diffraction and Thermo-gravimetry. The characterization study confirmed the formation of MSUM crystals in the experiments. Herbal extract solutions of Boswellia serrata Linn., Aerva lanata juss ex. Schult, Routula aquatica Lour. and Boerhavia diffusa Linn., were used for the growth inhibition study of MSUM crystals. Aqueous herbal extract solutions were poured as supernatant solutions along with the control solution on the set gels during the crystal growth experiment. The growth observations and the measurements of crystal dimensions using optical microscope suggested that Routula aquatica Lour. and Aerva lanata juss ex. Schult extracts exhibited good crystal growth inhibition results. Conclusion: Routula aquatica Lour. extract dissolved MSUM crystals after 15 days of pouring the supernatant solution on the gel. This in vitro study may be helpful for in vivo studies, which may further lead to develop a preclinical formulation for gout treatment.
\end{abstract}

Key words: Crystals, powder X-ray diffraction, FTIR, thermal stability, herbal extracts

\section{INTRODUCTION}

Gout is the term given to a group of metabolic conditions, in which the signs and symptoms results from the deposition of crystals of Monosodium Urate Monohydrate (MSUM) in various connective tissues and joints. It is also an auto inflammatory disorder associated with deposition of MSUM crystals in joints and periarticular tissues. The recent advances, however, suggest that the innate immune system may drive the gouty inflammatory response to $\mathrm{MSUM}^{[1,2]}$. The deposition of these crystals, result from the raised levels of uric acid in blood (hyperuricemia) and various body fluids. Hyperuricemia is not essential requirement of diagnosis of gout, but the risk of gout and its presence increases with the degree and duration of hyperuricemia. The risk factor of gout is also associated with the uric acid and urate compound nephropathy ${ }^{[3]}$. Nephropathy of uric acid and urate substances is associated with the formation of Monosodium Urate (MSU), ammonium urate and uric acid in urinary tract system. The MSU is rarely observed in renal calculi in spite of human urine often being supersaturated with monosodium urate $e^{[4-6]}$. Only exceptionally pure monosodium urate calculi have been described and these were of vesical origin ${ }^{[7]}$. Hyperuricosuria,

Corresponding Author: Mihir, J. Joshi, Crystal Growth Laboratory, Physics Department, Saurashtra University, Rajkot 360005, India 
Am. J. Infect. Dis., 5 (3): 225-230, 2009

simulated by the addition of dissolved sodium urate, promotes the crystallization of Calcium Oxalate. It could also act as an effective promoter of calcium oxalate crystallization according to in vitro experiments ${ }^{[8,9]}$.

A very few attempts have been made to grow the uric acid or urate crystals. Irusan et al. ${ }^{[10]}$ have reported the growth of ammonium urate crystals using the gel growth technique, whereas Kalkura et al. ${ }^{[1]}$ have reported the growth of spherulites of monosodium urate monohydrate and Kalkura et al. ${ }^{[12]}$ have studied crystallization of pure uric acid.

From this description of accumulated knowledge about the role of Monosodium Urate Monohydrate (MSUM) crystals in gout or gouty arthritis as well as urolithiasis, it is evident that till today there is no sufficient information available to clarify all aspects related to crystallization behavior under physiological conditions and its different characteristics. It is, therefore, important to grow and characterize MSUM crystals and study the inhibitive effect of various herbal extracts on its growth. The growth and inhibition study provides very useful information regarding the potent herbal extracts or herbal formulations, which can inhibit the growth of crystals in vitro and may be useful in prevention or cure of this crystal induce ailments.

\section{MATERIALS AND METHODS}

The growth of MSUM crystals is not widely reported. In the present investigation, glass test-tubes of $25 \mathrm{~mm}$ diameter and $150 \mathrm{~mm}$ length were used as crystal growth apparatus. Sodium metasilicate solution of 1.05 specific gravity and $0.2 \mathrm{M}, \mathrm{NaOH}$ solutions were added in equal amounts. This mixture was acidified by $2 \mathrm{~N}$, acetic acid in such manner that the $\mathrm{pH}$ values within 4.5-5.0 are obtained. This mixture was poured in equal volumes in different test tubes and allowed to set into the gel form. Within $48 \mathrm{~h}$, good quality gels were set. After setting the gel, the $0.07 \mathrm{M}$ uric acid solution was poured gently on that. Good quality needle shaped crystals were grown, which are shown in Fig. 1. The probable reaction for the formation of MSUM is as follows:

$$
\mathrm{NaOH}+\mathrm{C}_{5} \mathrm{H}_{4} \mathrm{~N}_{4} \mathrm{O}_{3} \rightarrow \mathrm{NaHC}_{5} \mathrm{H}_{2} \mathrm{~N}_{4} \mathrm{O}_{3} \cdot \mathrm{H}_{2} \mathrm{O}
$$

Different plants were selected for the preparation of extracts, which are Boswellia serrata Roxb (gum resin), Routula aquatica Lour. (roots) and Boerhaavia diffusa Linn. (roots) and Aerva lanata Juss ex. Schult (root). Hot aqueous extracts are obtained by taking $50 \mathrm{~g}$ of plant materials placed in a beaker and then $400 \mathrm{~mL}$ of distilled water was added to the plant

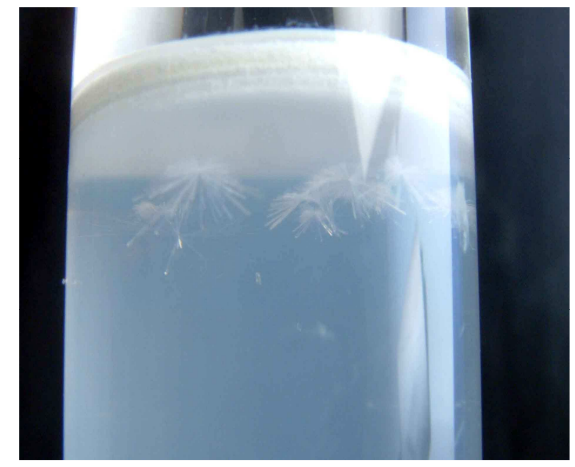

Fig. 1: Crystal growth of MSUM crystal

material in the ratio $1: 8$, which was heated in a boiling water bath until the kwath reduces in half of the original volume. All extracts were air dried in a rotary vacuum evaporator to a syrupy consistency and then in a steam bath to thick, pasty consistency. All extracts were stored in glass vials kept in air tight plastic boxes at $-20^{\circ} \mathrm{C}$.

Figure 1 shows the grown crystals. The crystals have been characterized by different techniques.

FT-IR spectrum was recorded on Shimadzu 8400 set up in 400-4000 $\mathrm{cm}^{-1}$ range using powdered samples in $\mathrm{KBr}$ medium. Powder XRD was carried out on Philips X'pert using $\mathrm{Cu} \mathrm{K}_{\alpha}$ radiation. Thermogram was recorded on Pyrif 1, Perkin Elmer, in atmosphere of air, from room temperature to $900^{\circ} \mathrm{C}$ at a heating rate of $15^{\circ} \mathrm{C} \mathrm{min}^{-1}$.

\section{RESULTS}

The molecular structure of MSUM is as Shown in Fig. 2. Figure 3 shows FT-IR spectrum of MSUM crystals. Table 1 gives assignments to the peaks.

From the FT-IR spectrum one can confirm the presence of keton group $(\mathrm{C}=\mathrm{O})$, carbon-nitrogen bond $(\mathrm{C}-\mathrm{N}), \mathrm{N}-\mathrm{H}$ stretching and rocking as well as the presence of water of hydration in the sample.

Figure 4 is the powder XRD pattern and Table 2 gives the data. The samples are highly crystalline in nature.

Figure 5 is the thermo-gram of MSUM, which shows that the compounds is stable up to $100^{\circ} \mathrm{C}$ and slowly give up water of hydration and on wards $170^{\circ} \mathrm{C}$ starts losing crystalline water immediately. The associated water molecule is completely removed at $240^{\circ} \mathrm{C}$ and becomes anhydrous. Subsequently, when the temperature is further increased, the mass loss occurs very sharply between $370-480^{\circ} \mathrm{C}$ with the release of gases like hydrogen cyanide, carbon dioxide and carbon monoxide. This is followed by a slow process between $480-750^{\circ} \mathrm{C}$ with loss of nearly $75-80 \%$ of original mass. 
Am. J. Infect. Dis., 5 (3): 225-230, 2009

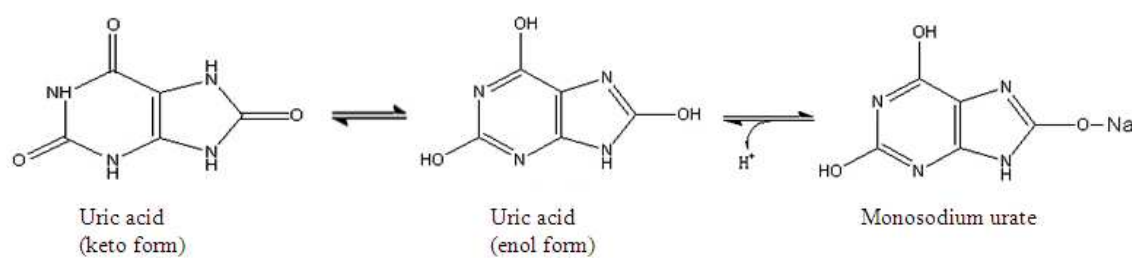

Fig. 2: Chemical structure of MSU

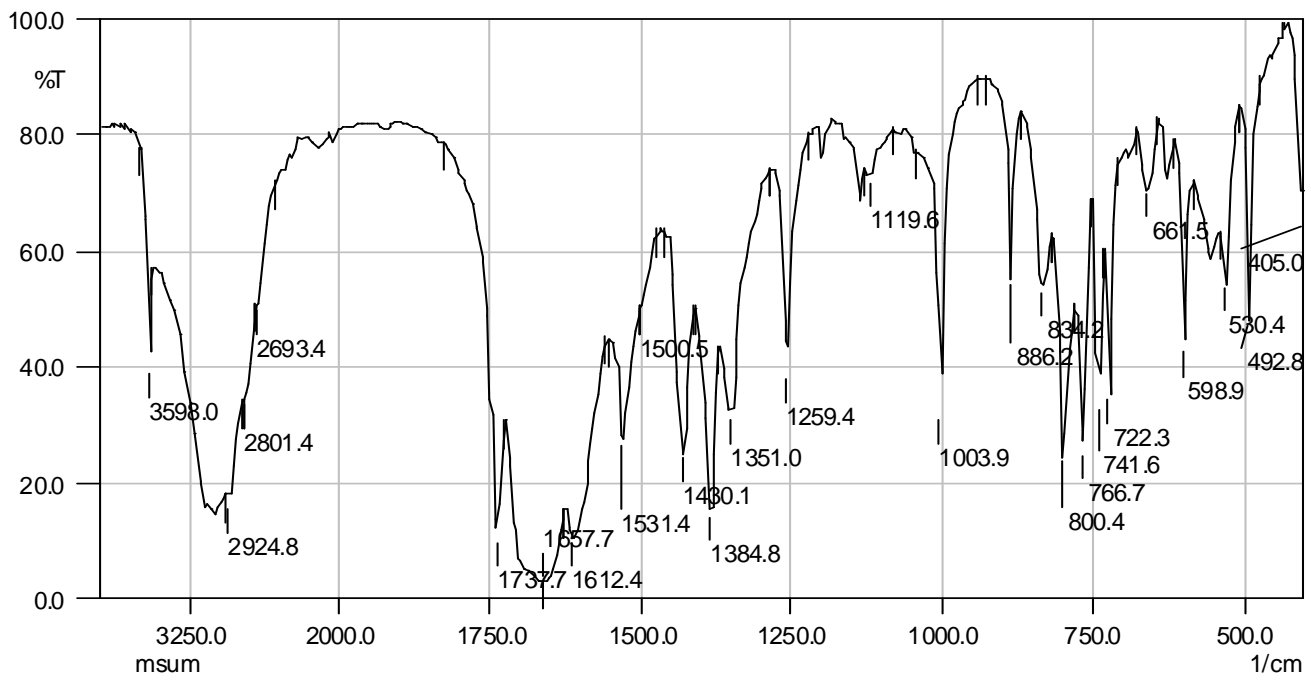

Fig. 3: Shows FT-IR spectrum of MSUM crystals

Table: 1 Assignments of observed absorptions in FT-IR spectrum Monosodium urate monohydrate $\mathrm{NaHC}_{5} \mathrm{H}_{2} \mathrm{~N}_{4} \mathrm{O}_{3}$

\begin{tabular}{ll} 
Assignments & Observed vibrational frequencies $\left(\mathrm{cm}^{-1}\right)$ \\
\hline $\mathrm{C}=\mathrm{O}$ & 1737.7 \\
$\mathrm{C}=\mathrm{C}$ & $1531.4,1500.5$ \\
$\mathrm{C}-\mathrm{N}$ & $1259.4,1351.0,1384.8$ \\
$\mathrm{~N}-\mathrm{H}$ stretching & 2924.8 \\
$\mathrm{~N}-\mathrm{H}$ rocking & $722.3,741.6,766.7,800.4,886.0,842.0$ \\
O-H stretching & 3598.0 \\
Oxygen-metallic bond & $400-600$ \\
\hline
\end{tabular}

Table 2: Powder XRD data of MSUM crystals

\begin{tabular}{llrl}
\hline $2 \theta$ & $\mathrm{d}(\AA)$ & Height & FWHM \\
\hline 9.3700 & 9.43082 & 73.4 & 0.5034 \\
11.600 & 7.62221 & 86.0 & 0.4947 \\
17.913 & 4.94785 & 93.5 & 0.5017 \\
18.889 & 4.69429 & 185.2 & 0.5381 \\
25.466 & 3.49486 & 95.9 & 1.2240 \\
26.121 & 3.40877 & 78.8 & 1.3220 \\
28.246 & 3.15688 & 476.9 & 0.5930 \\
29.316 & 3.04410 & 67.7 & 0.4938 \\
30.789 & 2.90170 & 75.7 & 0.8045 \\
33.632 & 2.66260 & 193.3 & 0.5999 \\
35.404 & 2.53332 & 69.4 & 1.6593 \\
36.390 & 2.46695 & 94.9 & 0.7224 \\
39.933 & 2.25581 & 57.8 & 0.6052 \\
40.948 & 2.20223 & 70.8 & 0.8910 \\
44.334 & 2.04158 & 86.2 & 0.6576 \\
53.773 & 1.70337 & 63.2 & 1.6051 \\
\hline
\end{tabular}

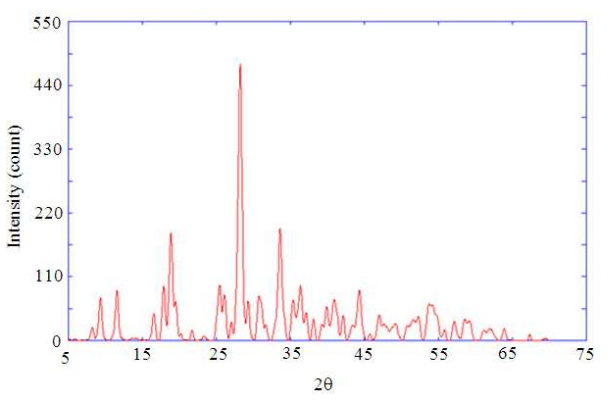

Fig. 4: Powder X-ray diffractogram of the MSUM crystals

Finally, it is converted into $\mathrm{Na}_{2} \mathrm{O}$, which remains stable up to the end of the analysis. One water molecule is found to be associated with the crystals.

However, no work is reported on the in vitro growth and inhibition study of MSUM crystals. Figure 6 shows the test tubes having the mixture of uric acid and solution of herbal extracts, which were used for inhibition study. In the case of pure uric acid the average length of grown crystals was $0.675 \mathrm{~cm}$. But for the $B$. serrata, containing supernatant solution, no considerable change was observed. The same effect was observed in the case of $B$. diffusa. 


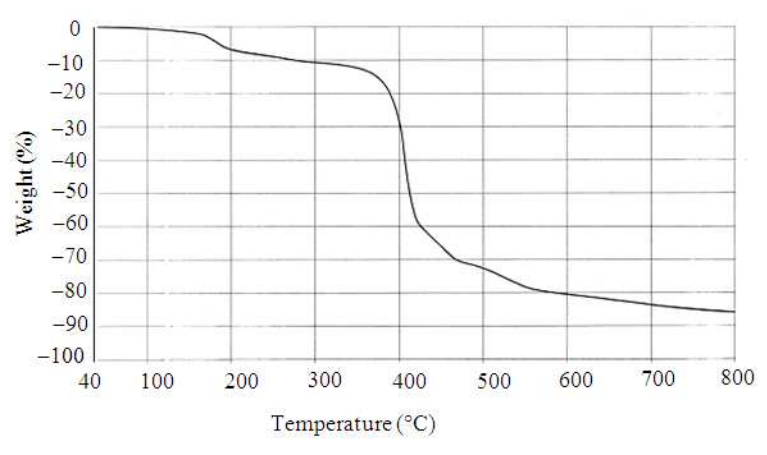

Fig. 5: Thermogram of the MSUM crystals

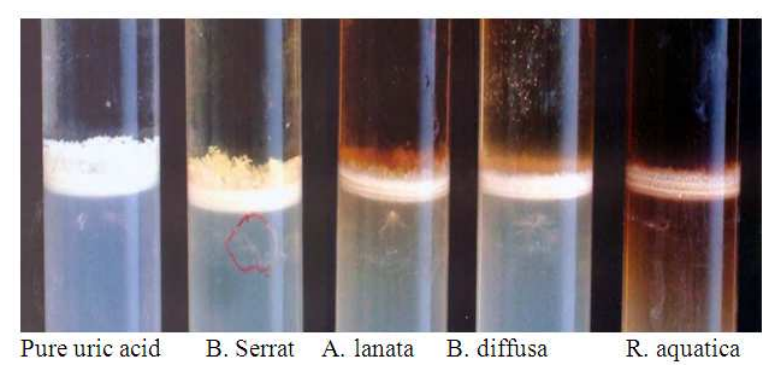

Fig. 6: Comparative study of growth inhibiton study of MSUM crystals

Table 3: Observed crystal length

\begin{tabular}{llll}
\hline Solutions & $\begin{array}{l}\text { Initial Length } \\
\text { of crystals }\end{array}$ & $\begin{array}{l}\text { Length of crystals } \\
\text { after 7 days }\end{array}$ & Remarks \\
\hline $\begin{array}{l}\text { Pure Uric acid } \\
\begin{array}{l}\text { B. serrata+ } \\
\text { Uric acid }\end{array}\end{array}$ & 0.675 & 0.675 & $\begin{array}{l}\text { No change } \\
\text { Minute change }\end{array}$ \\
$\begin{array}{l}\text { R. aquatica+ } \\
\text { Uric acid }\end{array}$ & 0.664 & 0.653 & $\begin{array}{l}\text { After 15 days } \\
\text { crystals completely } \\
\text { dissolved } \\
\text { Minute change }\end{array}$ \\
$\begin{array}{l}\text { B. diffusa+ } \\
\begin{array}{l}\text { Uric acid } \\
\text {. lanata+ }\end{array}\end{array}$ & 0.600 & 0.812 & $\begin{array}{l}\text { Remarkable } \\
\text { change }\end{array}$ \\
Uric acid & 0.865 & 0.586 & 0.768 \\
\hline
\end{tabular}

Result of inhibition study of MSUM crystals in terms of observed crystal length after seven days of pouring the herbal extract solutions is shown in Table 3. From the Table 3, one can easily conclude that $R$. aquatica and $A$. lanata give comparatively good inhibition than the others. However, the ethanolic herbal extract solutions almost gave the same results. As uric acid is completely insoluble in ethanol, it was observed that by adding ethanolic extract the reprecipitation occurred in the supernatant solution. But aqueous extract of $B$. diffusa $\left(80 \mathrm{mg} \mathrm{mL}^{-1}\right)$ was found mildly active. These results were found to be encouraging for the in vivo studies and the formulation of the drug. This study may be helpful to design the therapies for the prevention and cure of gout.

\section{DISCUSSION}

Monosodium urate (MSU, $\mathrm{NaHC}_{5} \mathrm{H}_{2} \mathrm{~N}_{4} \mathrm{O}_{3}$ ) is a white powder and soluble in water to the extent up to $120 \mathrm{mg} \mathrm{dL}{ }^{-1[13]}$, for the sake of comparison a much more limited solubility of uric acid in water is reported ${ }^{[14]}$, which is only $6.5 \mathrm{mg} \mathrm{dL}^{-1}$. Allen et al. ${ }^{[15]}$ have found that urate solubility in solutions of $140 \mathrm{mEq} \mathrm{L} \mathrm{L}^{-1}$ sodium content is temperature dependent, with a two fold drop in solubility between 37 and $25^{\circ} \mathrm{C}$. Moreover, Wilcox et al.$^{[6]}$ have carefully reinvestigated the solubility of uric acid and monosodium urate and have found that both are dependent on $\mathrm{pH}$. Uric acid is more soluble with increasing $\mathrm{pH}$, whereas the MSU is less soluble. The solubility of urate in plasma is somewhat greater than the saturation value in aqueous solutions of $0.13 \mathrm{M}$ sodium. Actual determination of solubility of monosodium urate in human plasma (or serum) indicates that the saturation occurs at concentrations about $7 \mathrm{mg} \mathrm{dL}{ }^{-1[16-18]}$. Monosodium urate mainly forms due to the reaction between the $\mathrm{Na}^{+}$ ion and the urate ion of uric acid. Due to limited solubility of uric acid in any known solvent it is difficult to grow MSUM crystals.

Grases et $a l^{[19]}$ have studied the structure of urate renal calculi after precipitation of ammonium and sodium urate from the synthetic urine; on the other hand, Grover et al. ${ }^{[20]}$ have studied the in vitro growth of calcium oxalate crystals in the presence of preincubated seed crystals of uric acid and MSU with undiluted human urine.

FT-IR spectroscopy is an excellent tool to identify various chemical bonds in a compound. Kalkura et al..$^{[1]}$ have reported the IR spectra of spherulites of monosodium urate monohydrate. The FTIR spectroscopic study has proved the presence of all functional groups and bonds in MSUM crystals.

Howell et al. ${ }^{[21]}$ have reported the powder XRD patterns and $\mathrm{d}$ values of uric acid, MSUM and Disodium Urate Dihydrate (DSUD), but unit cell parameters were not reported. The Powder XRD of tophaceous deposits in gout also pin points MSUM as the prime accuse. It is very difficult to obtain the single crystal XRD data on the present MSUM crystals because they get degraded immediately upon removal from the test tube upon exposure of the atmosphere. However, the present powder XRD study suggests that samples are crystalline in nature.

Thermogravimetric Analysis (TGA) is performed to assess the thermal stability of the substance. Earlier, Schneitzler et al. ${ }^{[22]}$ have reported TGA of purine derivatives such as aminophylline, theoophylline, caffeine and uric acid. It was found that uric acid was 
stable up to $375^{\circ} \mathrm{C}$ and thereafter the mass loss occurred through rapid process. However, the MSUM crystals having one water molecule associated with it and became anhydrous at $240^{\circ} \mathrm{C}$ and above $370^{\circ} \mathrm{C}$ the mass loss became very rapid. The stabilities of uric acid and MSUM are comparable.

The growth and inhibition study of various biomaterial crystals, particularly, responsible for ailments related to urinary stones were studied. Joshi et al. ${ }^{[23]}$ reported the effect of herbal extracts on the growth of calcium oxalate as well as struvite type urinary crystals by Chauhan et al. ${ }^{[24]}$. Recently, Parekh et al. ${ }^{[25]}$ have reported the growth inhibition of hydroxyapatite crystals by herbal extracts. From the Table 3, one can easily notce that $R$. aquatica and $A$. lanata give comparatively good inhibition than the others. However, the ethanolic herbal extract solutions almost gave the same results. As uric acid is completely insoluble in ethanol, it was observed that by adding ethanolic extract the re-precipitation occurred in the supernatant solution. But aqueous extract of $B$. diffusa (80 $\mathrm{mg} \mathrm{mL}^{-1}$ ) was found mildly active. These results were found to be encouraging for the in vivo studies and the formulation of the drug. This study may be helpful to design the therapies for the prevention and cure of gout.

\section{CONCLUSION}

The growth of MSUM crystals was carried out by using single diffusion gel growth technique, which is well suited to mimic the conditions of the growth of crystals in vivo. Very thin, transparent, needle type crystals are observed near the gel-liquid interface. FTIR spectrum of MSUM crystals confirms the presence of a water molecule, metal-oxygen bond, $\mathrm{O}-\mathrm{H}$ stretching, N-H rocking and stretching, $\mathrm{C}=\mathrm{C}$ bond, $\mathrm{C}=\mathrm{O}$ carbonyl group (keton group) and $\mathrm{C}-\mathrm{N}$ bond. The powder XRD results confirm the crystalline nature of the sample. MSUM crystals are thermally unstable and finally decompose into $\mathrm{Na}_{2} \mathrm{O}$. One water molecule is associated with the crystal. . In the case of $1 \%$ aqueous extract solutions of $B$. serrata and $B$. diffusa the inhibition was not significant, but in the case of $1 \%$ aqueous extract solutions of $R$. aquatica and A. lanata, good amount of inhibition was shown. Till today there is no major remedy is available to dissolve the MSUM crystal in synovial fluid, which is responsible for gout. This study may help the prevention or cure of gout.

\section{ACKNOWLEDGEMENT}

The researchers are thankful to Department of Biotechnology, Government of India, New Delhi, for research grants and Prof. K. N. Iyer and Prof. H.H. Joshi for their keen interest. The author (BBP) is thankful to the authority of Pandit Deendayal Petroleum University for the encouragements

\section{REFERENCES}

1. Martinon, F. and L.H. Glimcher, 2006. Gout: New insights into an old disease. J. Clin. Invest., 116: 2073-2075. DOI: 10.1172/JCI29404

2. Underwood, M., 2006. Diagnosis and management of gout. Br. Med. J., 332: 1315-1319. DOI: 10.1136/bmj.332.7553.1315

3. Rosenthal, A.K., 1998. Crystal Arthropathies, Textbook of Rheumatology. Oxford University Press, Oxford, pp: 1560-1561.

4. Coe, F.L., A.L. Strauss, Vrishali Tembe and Siok Le Dun, 1980. Uric acid saturation in calcium nephrolithiasis. Kidney Int., 17: 662-668. DOI: 10.1038/ki.1980

5. Pak, C.Y.C., O. Waters, L. Arnold, K. Holt, C. Cox and D. Barilla, 1977. Mechanism for calcium urolithiasis among patients with hyperuricosuria: Supersaturation of urine with respect to monosodium urate. J. Clin. Invest., 59: 426-431. DOI: 10.1172/JCI108656

6. Wilcox, W.R., A. Khalaf, A. Weinberger, I. Kippen and J.R. Klinenburg, 1972. Solubility of uric acid and monosodium urate. Med. Biol. Eng., 10: 522-531. DOI: $10.1007 / \mathrm{BF} 02474201$

7. Cifuentes, L., 1984. Composition and Structure of the Calculations Renals. Salvat, Barcelona, pp: 87.

8. Grover, P.K., R.L. Ryall and V.R. Marshall, 2003. Dissolved urate salts out calcium oxalate in undiluted human urine in vitro. Chem. Biol., 10: 271-278. DOI: 10.1016/S1074-5521(03)00057-7

9. Martins, M.C., A.A. Meyers, N.A. Whalley and A.L. Rodgers, 2002, Crystine: A promoter of the growth and aggregation of Calcium Oxalate crystals in normal undiluted human urine. Invest. Urol., 167: 317-321. DOI: 10.1016/S00225347(05)65461-4

10. Irusan, T., D. Arivuoli and P. Ramasamy, 1993. Microhardness studies on ammonium acid urate crystals. J. Mater. Sci. Lett., 12: 405-406. DOI: 10.1007/BF00609167

11. Kalkura, S.N., E.K. Girija, M. Kanakavel and P. Ramasamy, 1995. In vitro crystallization of spherulites of monosodium urate monohydrate. J. Mater. Sci. Med., 6: 577-580. DOI: 10.1007/BF00121281

12. Kalkura, S.N., V.K. Vaidyan, M. Kanakavel and P. Ramasamy, 1993. Crystallizatiion of Uric acid. J. Cryst. Growth., 132: 617-620. DOI: 10.1016/0022-0248(93)90092-B 
13. Kirk Othmer, 1970. Encyclopedia of Chemical Technology. Interscience, Division of John Willey and Sons Inc., New York, pp: 107-119.

14. Peters, J.P. and K.K. Van Siyke, 1946. Quantitative Clinical Chemistry. Williams and Wilkins Company, Baltimore, pp: 937.

15. Allen, D.J., G. Milosovich and A.M. Mattocks, 1965. Inhibition of monosodium urate needle crystal growth. Arthritis Rheum., 8: 1123-1133. DOI: 10.1002/art.1780080611

16. Seegmiller, J.E., 1965. The acute attack of gouty arthritis. Arthritis Rheum., 8: 714-725,DOI: 10.1002/art.1780080452

17. Wyngaraden, J.B., 1965. Xanthine oxidase in hibitors in the management of gout. Arthritis Rheum., 8: 883-890. DOI: 10.1002/art.1780080452

18. Killenberg, 1965. The effectiveness of allopurinol in the treatment of gout. Arthriris Rheum, 8: 891-895. DOI: 10.1002/art.1780080453.

19. Grases, F., A.I. Villacampa and Costa-Bauza, 1999. Ammonium and sodium urates precipitating from synthetic urine and fine structure of urate renal calculi. Urol. Res., 27: 141-147. DOI: 10.1007/s002400050100

20. Grover, P.K., R.L. Ryall and V.R. Marshall, 1992. Calcium oxalate crystallization in urine: Role of urate and glycosaminoglycans. Kidney Int., 41: 149-154. DOI: $10.1038 / \mathrm{ki} .1992 .20$
21. Howell, R.R., E.D. Eanes and J.E. Seegmiller, 1963. X-ray diffraction studies of the tophaceous deposits in gout. Arthrirtis Rheum., 6: 97-103. DOI: wiley.com/10.1002/art.1780060202

22. Schnitzler, E., M. Kobelnik, G.F.C. Sotelo, G. Bannach and M. Ionashiro, 2004. Thermo analytical study of purine derivatives compound. Ecl. Quim, Sao Paulo, 29: 71-78. DOI: 10.1590/50100467020040001-00009

23. Joshi, V.S., B.B. Parekh, M.J. Joshi and A.B. Vaidya, 2005. Herbal extracts of Tribulus terrestris and Bergenia ligulata inhibit the growth of calcium oxalate monohydrate crystals in vitro. J. Cryst. Growth, 275: e-1403-e-1408. DOI: 10.1016j.jerysgro.2004.11.240

24. Chauhan, C.K., M.J. Joshi and A.D.B. Vaidya, 2008. Growth inhibition of struvite crystals in the presence of herbal extract commophora wightii,J. Mate. Sci. Matee. Med. http://www.ncbi.nlm.nih.gov/pubmed/18568390

25. Parekh, B.B., Mihir Joshi and Ashok Vaidya, 2008. Characterization and inhibitive study of gel-grown hydroxyapatite crystals at physiological temperature. J. Cryst. Growth, 310: 1749-1753. DOI: 10.1016j.jcrysgro2007.11.219 